\title{
Additive manufacturing (3D printing) in superficial brachytherapy
}

\author{
Robert Bellis, MBA', Agata Rembielak, MD, PhD, MRCR2,3, Elizabeth A. Barnes, MD, FRCPC ${ }^{4}$, Moti Paudel, PhD5 \\ Ananth Ravi, PhD 6 \\ 'Department of Physics, Ryerson University, Toronto, Canada, ${ }^{2}$ Department of Clinical Oncology, The Christie NHS Foundation Trust, \\ Manchester, UK, ${ }^{3}$ Division of Cancer Sciences, The University of Manchester, Manchester, UK, ${ }^{4}$ Department of Radiation Oncology, Odette \\ Cancer Centre, Sunnybrook Health Sciences Centre, University of Toronto, Toronto, Canada, ${ }^{5}$ Department of Radiation Oncology, University \\ of Toronto, and Department of Medical Physics, Sunnybrook Health Sciences Centre, Toronto, Ontario, Canada, ${ }^{6}$ Department of Radiation \\ Oncology, University of Toronto, Toronto, Ontario, Canada
}

\begin{abstract}
The aim of this work is to provide an overview of the current state of additive manufacturing (AM), commonly known as 3D printing, within superficial brachytherapy (BT). Several comprehensive database searches were performed to find publications linked to AM in superficial BT. Twenty-eight core publications were found, which can be grouped under general categories of clinical cases, physical and dosimetric evaluations, proof-of-concept cases, design process assessments, and economic feasibility studies. Each study demonstrated a success regarding AM implementation and collectively, they provided benefits over traditional applicator fabrication techniques. Publications of AM in superficial BT have increased significantly in the last 5 years. This is likely due to associated efficiency and consistency benefits; though, more evidences are needed to determine the true extent of these benefits.
\end{abstract}

J Contemp Brachytherapy 2021; 13, 4: 468-482 DOI: https://doi.org/10.5114/jcb.2021.108602

Key words: additive manufacturing, 3D printing, brachytherapy, skin, superficial, applicator, keratinocyte carcinoma.

\section{Purpose}

\section{Skin cancer}

Keratinocyte carcinoma (KC), or cancer deriving from keratinocytes of the skin, is the most common type of cancer worldwide. Keratinocyte carcinoma consists mainly of basal cell carcinoma (BCC) and cutaneous squamous cell carcinoma (cSCC) [1]. Recently, KC term has been gradually replacing non-melanoma skin cancer (NMSC), as it better reflects the specific (keratinocyte) origin of the cancer [2]. Even though most cancer registries in North America and other countries do not collect data on many $\mathrm{KCs}$ due to difficulties in tracking case and relative success of most treatments [3], some estimate that over 5 million patients are diagnosed every year solely in the USA [4], with many patients having more than one $\mathrm{KC}$ diagnosis [5]. Surgery is the standard treatment modality for $\mathrm{KC}$. The main goal of treatment is to remove cancerous lesions while maintaining cosmesis and tissue function [6]. There are, however, instances, where surgical techniques would yield inadequate resection of the lesion, or possibly poor cosmetic or functional outcomes due to location of disease. Some patients may not be eligible for surgery because of associated comorbidities or they simply refuse such treatment. In these cases, radiation therapy can play a prominent role in the treatment of $\mathrm{KC}$, using external beam radiation therapy (EBRT) with electrons, photons, superficial, or orthovoltage radiation, which can all successfully treat KC. However, irregular topologies with sharp gradients can present problems when attempting to distribute a therapeutic dose using EBRT homogenously and limit the dose to surrounding tissues. In these specific cases, brachytherapy (BT), the treatment of a lesion using radioactive sources placed adjacent to or directly within cancer, can be used to achieve high control rates as well as promising cosmetic and/or functional results [7].

\section{Brachytherapy}

There are two primary types of BT for the treatment of skin, including superficial and interstitial $[8,9]$, and the depth of disease determines which type is appropriate. Interstitial BT, where catheters are directly implanted in the lesion, is warranted generally for skin lesions $\geq 5 \mathrm{~mm}$ in thickness, which is out of the scope of this article [10]. Superficial BT, also known as 'contact BT' or 'plesiotherapy', is the use of radionuclide or electronic sources to 
treat cancerous lesions $<5 \mathrm{~mm}$ in thickness [6]. These sources are guided through catheters in a specialized mould, or an applicator temporarily affixed to the skin. Common radiation source types include iridium-192 and cobalt-60 [9]. GEC-ESTRO ACROP recommendations in skin brachytherapy states that for lesions less than $5 \mathrm{~mm}$ in thickness, standard surface applicators and flaps are indicated on regular surfaces, while customized applicators can be used for irregular sides [10].

Brachytherapy offers many known benefits over EBRT, such as rapid dose fall-off with distance from the source, thus reducing dose to underlying tissues and nearby organs at risk, hypo-fractionated treatments' regimens, which yield comparable efficacy and cosmetic results $[11,12]$ while limiting patient visits, and customized applicators that can conform to the variable contours of the skin, allowing better approximation to skin surface. In superficial BT studies, for small and shallow KC lesions, local control ranged from $96.2 \%$ to $100 \%$ for up to 66 months of follow-up [13-21]. Additionally, superficial BT has been shown to offer superior results in terms of conformity, dose coverage, and tissue sparing ability compared to EBRT when treating areas of the head and neck, especially the nose and ear lobes [22].

There is a growing trend towards digitally designing applicators tailored to each patient's unique anatomy and employing additive manufacturing (AM) techniques, commonly referred to as '3D printing'. This review discusses AM and its association with superficial high-doserate (HDR) BT, applicator creation process, quality assurance measures, and clinical applications.

\section{Traditional applicators - benefits and drawbacks}

Many cancer centers use standardized applicators for superficial BT treatment. Flexible, flap-like applicators are commercially available. These are a viable option for some large skin cases, due to consistent catheter spacing and flexibility as well as the ability to cut the flap to specific dimensions or affix it to other immobilization devices to improve reproducibility [23]. However, the flap applicators limit how close the sources can approach the skin and how well the flap geometry conforms to rapidly varying skin topology. Treating small areas is also challenging with these flap-based applicators. There are other commercial products available, such as Leipzig and Valencia conical applicators, which can treat small, planar areas $(2-3 \mathrm{~cm}$ diameter). Still, these are not ideal over variable topologies. For treatments of irregular, curved surfaces necessitating customized devices, skin applicators have taken the form of moulds manually crafted within a cancer center either by radiation therapists or dosimetrists. Manually creating a mould involves laboriously forming a stone or gypsum plaster replica of patient's anatomy, and then applying thin pieces of heated wax, plastic, or silicone [24] that are interweaved with catheter paths overtop the area of interest. Ensuring the catheter paths are consistently spaced and are at an appropriate distance from skin across the entire length of track can be challenging. Traditional manual mould preparation can also lead to air gaps between mould and skin surface and/or between mould layers.

\section{Additive manufacturing in superficial brachytherapy}

\section{Clinical need for additive manufacturing applicators}

The variations in contours among patients and the steep physical gradients in regions like the head and neck, where KCs are most common [25], necessitate customized BT solutions. Recently, with the rise of inexpensive yet robust mould creation options, more healthcare institutions have access to $\mathrm{AM}$ technology. AM is not new to radiation therapy nor limited to BT. Bolus [26], phantoms [27], immobilizers [28], and field-shaping devices [29] are a few of the other areas in RT, where AM technology has been incorporated. AM applicators are an attractive solution, as they enable almost exact replica of a patient's surface as well as fully customizable catheter tracks. These applicators can potentially lead to sophisticated dose modulation through precise catheter placement, achieving a more homogenous skin dose. There is a growing interest in the development of AM applicators for skin BT. There is, however, a lack of review articles, and the latest guidance document from AAPM and GECESTRO acknowledges that neither a standard of care nor comprehensive guideline exists yet for surface brachytherapy, let alone the inclusion of AM applicators [23].

\section{Current literature profile of additive manufacturing in superficial brachytherapy}

This paper is a review of the present state of AM in superficial skin BT. Keyword searches in the PubMed database with no date restrictions to find relevant articles were used. A publication was considered relevant for this review, if it discussed a clinical case, material dosimetric assessment, proof-of-concept study, or economic feasibility study of AM in superficial BT. PubMed was queried 4 times between January and June 2020. Medical subject heading search terms, included variations of 'brachytherapy', such as 'skin brachytherapy', 'plesiotherapy', 'contact brachytherapy', 'superficial brachytherapy', and 'interventional radiotherapy'. The general search terms 'mould/mold' and 'applicator' were also used in the searches. Technology-specific search terms included 'additive manufacturing', '3D/three-dimensional printing', 'fused deposition modeling', and 'stereolithography'. Figure 1 shows an example of a database query. While there were generally very few results for each group of search terms, there were many different groups of terms that yielded different, yet relevant publications.

After including additional abbreviated keywords, 28 publications were found for AM in superficial skin BT, which formed the basis of this review. These included 8 clinical case studies [30-37], 7 physical and dosimetric evaluations [38-44], 6 proof-of-concept cases [45-50], 6 design process assessments [51-56], and 1 economic feasibility study [57]. All these articles, except for one, were published since 2015. In a similar review of three-dimensional printing use throughout the entire field of radiation oncology, 21 publications were discussed relating to general BT applicators [58], with the vast majority of these also originating from the last 5 years. AM in superficial BT 


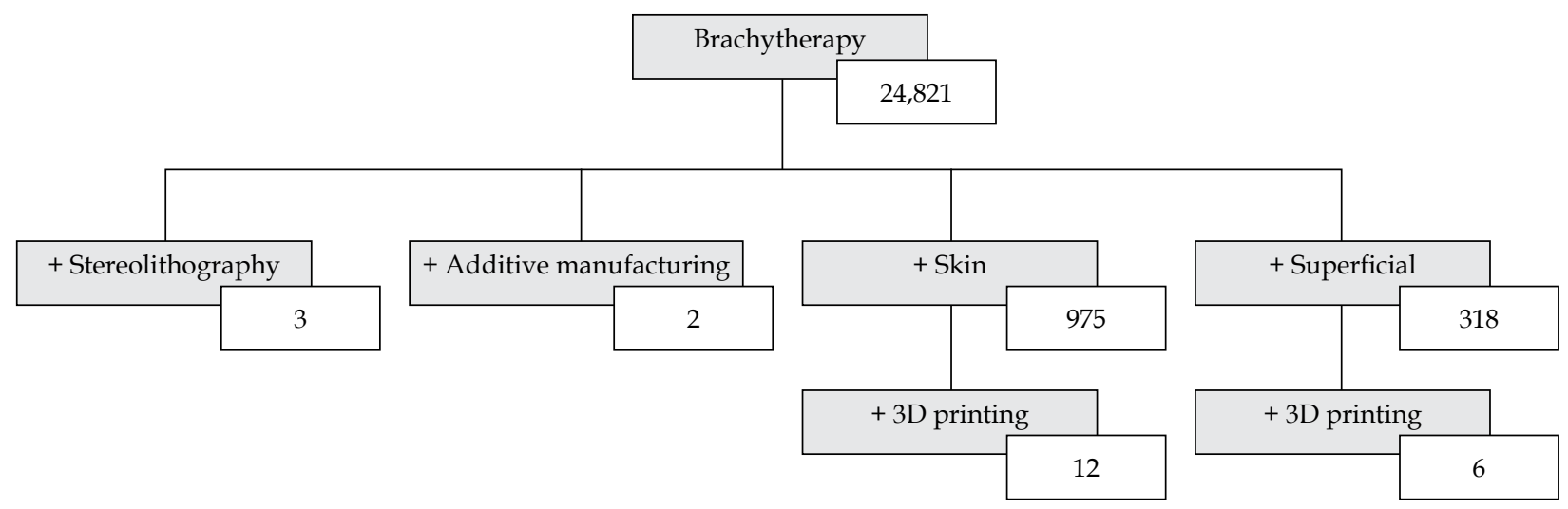

Fig. 1. Keywords and the resultant number of publications found through searches in the PubMed database up to July 2020. $(+)$ denotes adding a term to a parent search term

as well as radiation oncology in general is in its early stages but quickly gaining clinical interest and recognition.

\section{Benefits over conventional moulds}

Additive manufacturing offers many benefits over hand-fabricated moulds, mainly that production of the applicators is consistent and reproducible. Additionally, multiple virtual moulds can be created to determine which would best suit a patient's anatomy with ease, and dosimetry can be optimized prior to fabrication. In contrast, significant changes to a manual mould after its completion take considerable effort or requires another mould altogether. Although AM applicators can take several hours to print, the printing can be done without oversight. Furthermore, AM applicators can be designed directly from a patient's contours from computed tomography (CT) scans or direct surface scanning technologies. The patient only needs to be present for a quick, contactless scan, as opposed to extended episodes of making a plaster cast of the area in question [57]. The custom AM applicators can be designed to fit tightly and securely to the skin, minimizing air gaps better than conventional approaches, even when there are slight variations in anatomy [42]. Furthermore, the offset between the catheters and the skin surface of the patient can be carefully adjusted to achieve a higher dose to more deep-seated tumors, or to achieve sharper dose drop-off adjacent to organs at risk and reduce risk of air gaps. Given the digital nature of AM applicators, constant catheter distance and spacing across the target surface are possible enabling predictable dose modulation, and better agreement between planning goals and delivered dosimetry [33]. Further, AM enables the option of incorporating shielding into the applicator - the initial print can have cavities that can be filled with shielding materials [30,33]. Lastly, most of the AM applicator creation process is digital. This can potentially lead to sharing of code and digital workflows. Naturally, there is a significant potential for automation and optimization in the future.

\section{Process of additive manufacturing}

According to the International Organization for Standardization (ISO) and the American Society for Testing of Materials (ASTM), AM is the "process of joining materials to make parts from 3D model data, usually layer upon layer" [59]. In regards to the term '3D printing', the latest standards document, ISO/ASTM 52900-15, states that it is "the fabrication of objects through the deposition of a material using a print head, nozzle, or another printer technology" but also notes that the term "is often used in a non-technical context synonymously with AM; until present times this term has in particular been associated with machines that are low end in price and/or overall capability" [59]. Simply, it is a general term that describes only a subset of technologies within the broader family of AM [60]. This widespread adoption of the term '3D printing' in medicine to refer to all AM processes may present a barrier in the future, namely for knowledge dissemination and research [61].

Outside of medicine, AM has existed for many years, and several groups of AM-based technologies have been established. The first type of AM was developed in the 1980s by Charles Hull. Through his company, 3D Systems, Inc., Hull patented a technique known as 'stereolithography' in 1986, which was able to create plastic prototypes much quicker than the traditional techniques of formative or subtractive manufacturing, without their associated imperfections [62]. Since 1986, there have been many AM techniques developed, with the commonality that a 3-dimensional object is constructed sequentially, a single-layer at a time.

According to the ASTM, there are 7 distinct groups of AM technologies based on the process of layer formation of the resultant object [63]. These categories include vat photopolymerization, material extrusion, powder bed fusion, sheet lamination, binder jetting, material jetting, and directed energy deposition. Moreover, each category is composed of several similar proprietary and open-source technologies [64]. Material extrusion (ME), the "process, in which material is selectively dispensed through a nozzle or orifice" [59], is the most common form of AM used in radiation oncology [65] and superficial BT. Within ME, the major technology is fused filament fabrication (FFF). FFF is equivalent to fused deposition modeling (FDM), currently a trademark of Stratasys, Inc. FFF use is generally widespread because of relatively low associated costs, acceptable resolutions, and suitable physical and dosimetric 
properties of the materials involved [65] compared to other technologies. Vat photopolymerization (VP), the "process, in which liquid photopolymer in a vat is selectively cured by light-activated polymerization" [59], and material jetting (MJ), the "process, in which droplets of build material are selectively deposited" [59], are also seen to a lesser extent through stereolithography apparatus (SLA) and PolyJet (PJ) technologies, respectively. The other AM processes are not currently used in superficial BT, and instead, are likely deployed for highly precise industrial tasks with more robust materials, such as lasered metal powders for jet engine component creation [66]. Furthermore, each technology requires different types of materials, with some crossover among the technologies. Material selection considerations, such as biocompatibility, sterilization, and dosimetric properties as well as other physical characteristics will be further detailed in the quality assurance section of this review. Until recently, most AM methods have been restricted to industrial manufacturing companies that had the necessary capital and the expertise to purchase and operate the expensive equipment. With the rapid progress within the field of AM, purchasing desktop AM devices, such as FFF machines, is now economically feasible for healthcare facilities.

\section{Components of additive manufacturing in creation of superficial brachytherapy applicators}

The general workflow presented in the existing literature for generating AM applicators can be described in 3 steps: 1. Patient's anatomy modelling - obtaining a surface or CT scan and identifying the target; 2 . Digital processing of patient data - designing the print and sending the instructions to the printer; and 3. Printing the physical applicator - physically forming the object. The following sections discusses the various ways, in which these three steps have been clinically implemented. A summary of pertinent information is shown in Table 1.

\section{Modelling patient's anatomy}

Presently, disease depth and appropriateness for superficial BT are determined by combining information from physical examination, high-resolution CT/ magnetic resonance imaging (MRI) scans containing fiducial wires over the lesion or surgical scar, biopsy results, and high-frequency ultrasound (US). The American Brachytherapy Society (ABS) guidelines state that the lesion thickness, including a $1 \mathrm{~mm}$ uncertainty margin should not exceed $4-5 \mathrm{~mm}$ in order to be treated by superficial BT [6]. Once the lesion is deemed appropriate for skin BT, the challenge is to simulate patient's anatomy in order to begin designing the applicator.

\section{CT imaging}

The initial CT scan is commonly used to model patient anatomy as a starting point to design the mould. The slice thickness, an in-plane resolution, has implications for the smoothness of applicator and, subsequently, the fit to patient's unique anatomy. Modern computed tomography systems are capable of $0.5 \mathrm{~mm}$ spatial resolution in each plane [67]. But even with sub-millimeter resolution, other difficulties present themselves. Window and levelling often change the perceived edge of the skin surface. Determination of the true surface of patient can be subjective, and window/level modifications can change the perceived surface by 1-2 mm, as demonstrated in Figure 2 . Fusing MR or US with CT images can be performed to improve image clarity, but achieving an accurate fusion near the skin surface is difficult [6]. Additionally, image artefacts, which are especially common from the presence of fiducial wires on the skin, can further distort the surface. The standard CT-based workflow involves a CT scan to help design the applicator, followed by a subsequent scan after the applicator has been printed to verify the fit and planning.

\section{$3 D$ surface scanning}

Where available, the simulation CT scan has been replaced in favor of a quicker surface scan technique. These non-ionizing surface scans offer an alternative to reduce dose to the patient and improve workflow efficiencies $[32,53]$. There are 3D surface scanning technologies that can obtain surface topology from handheld devices. A process for AM applicator creation from an optical scanning device was proposed as early as 2006 by Schreiber et al. [51]. Surface scanning devices are becoming more common in medicine [68]. In radiation therapy, they have emerged as an inexpensive and efficient way to acquire an accurate surface scan in less than a minute [69]. Types of scanners that are feasible for topology acquisition in superficial BT are based on structured light 3D scanning, which measures distances by assessing the reflections of light or infrared rays. Photogrammetry, a similar technique for gaining topological information, has been shown to be a feasible option as well. Photogrammetry uses many photographs from multiple angles to distinguish distances between many points on the images. Douglass et al. implemented it in the design of a AM superficial applicator, and noted that the scan was within $0.1 \%$ and $2.6 \%$, when compared to CT scan values for volume and surface area, respectively [53].

There are some minor drawbacks to using a surface scanner. They can only provide topological information where they have a direct line of sight, and therefore cannot accurately operate within skin folds. Additionally, thick hair may be incorrectly assessed as a surface [70]. For some scanners, the distance that the object is scanned may affect the quality of the scan itself. Sharma et al. overcame this by creating a custom scanning gantry to consistently obtain the optimal scanning range for peak image quality and accuracy [69]. Overall, there are few disadvantages to surface scanning instead of CT imaging to acquire topological data for print design; however, after the applicator has been constructed, it is still advisable to conduct a planning CT to verify the fit.

\section{Surface alginate impressions}

For some sites, like the finger or penis, scanning technologies alone can be inadequate in providing accurate contour information. For these cases, negative impres- 


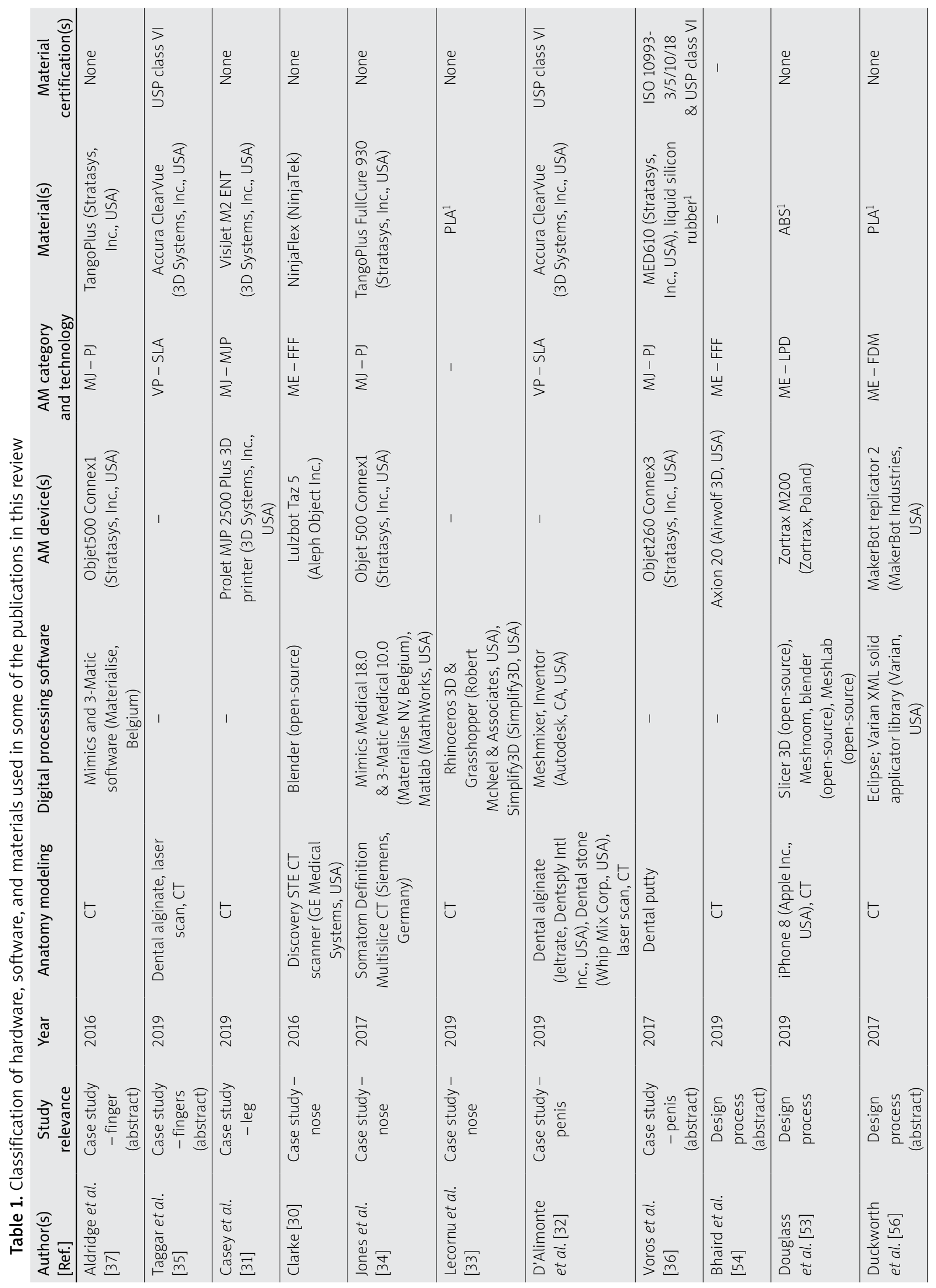




\begin{tabular}{|c|c|c|c|c|c|c|c|c|c|c|c|c|c|}
\hline 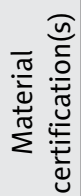 & \begin{tabular}{|l}
0 \\
¿े \\
2.
\end{tabular} & 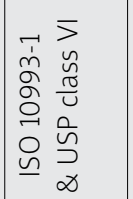 & 1 & 1 & 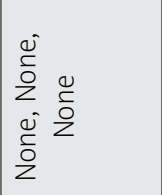 & 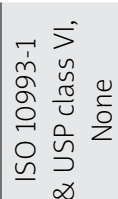 & $\begin{array}{l}0 \\
\text { Oे } \\
2\end{array}$ & 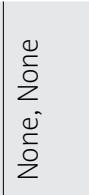 & 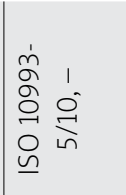 & $\begin{array}{l}\frac{0}{0} \\
\text { ¿े }\end{array}$ & 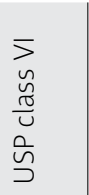 & 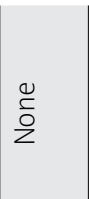 & 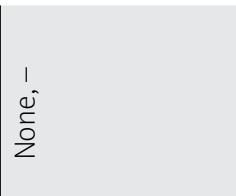 \\
\hline $\begin{array}{l}\frac{\pi}{0} \\
\frac{\pi}{\frac{\pi}{2}} \\
\frac{\pi}{2} \\
\frac{\pi}{2}\end{array}$ & 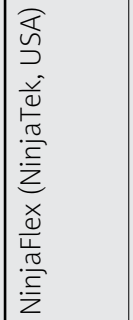 & 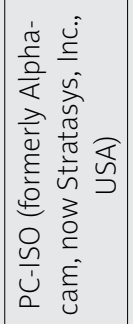 & 1 & 1 & 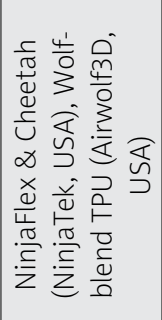 & 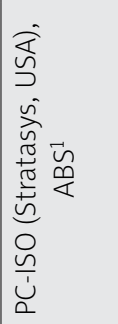 & 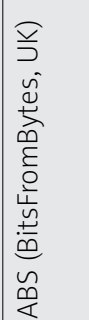 & 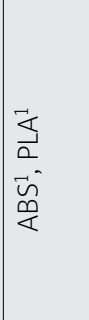 & 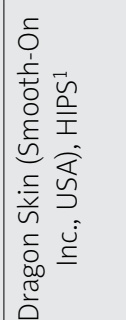 & $\begin{array}{l}\overrightarrow{\tilde{\alpha}} \\
\tilde{\alpha}\end{array}$ & 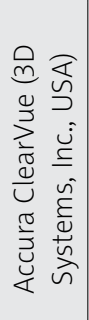 & $\begin{array}{l}\overrightarrow{\tilde{n}} \\
\stackrel{\alpha}{\alpha}\end{array}$ & 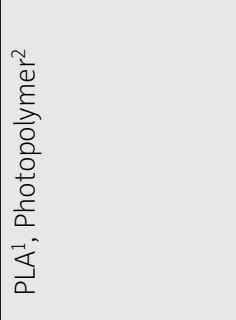 \\
\hline 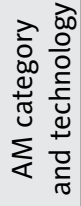 & \begin{tabular}{|l} 
岀 \\
1 \\
\\
㞫
\end{tabular} & \begin{tabular}{|l}
$\Sigma$ \\
0 \\
0 \\
1 \\
$山$ \\
$\Sigma$
\end{tabular} & 1 & 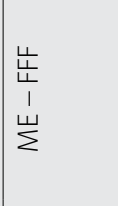 & 1 & 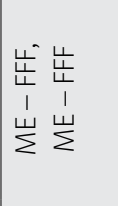 & 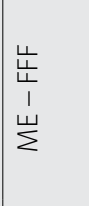 & \begin{tabular}{|l}
$\frac{u}{4}$ \\
1 \\
\\
\\
$\Sigma$
\end{tabular} & $\begin{array}{l}0 \\
\vdots \\
1 \\
\stackrel{\Delta}{\Sigma}\end{array}$ & $\begin{array}{l}\text { 岀 } \\
1 \\
\stackrel{山}{\Sigma} \\
\sum\end{array}$ & $\begin{array}{l}5 \\
n \\
1 \\
\infty\end{array}$ & & 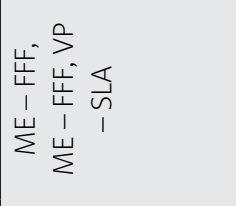 \\
\hline 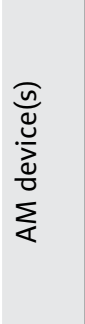 & 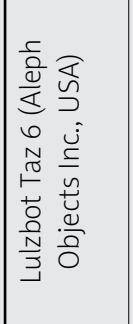 & 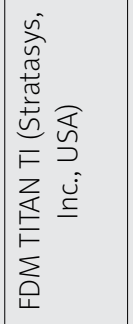 & 1 & 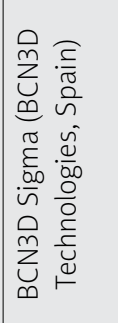 & 1 & 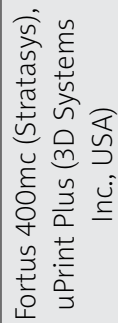 & 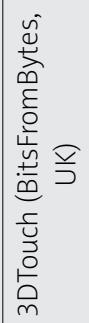 & 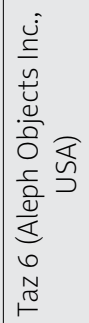 & 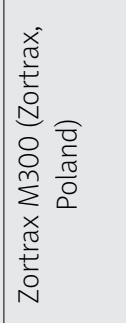 & 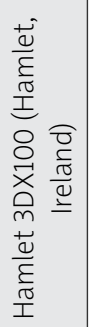 & 1 & 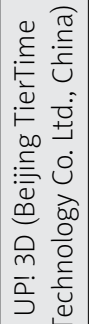 & 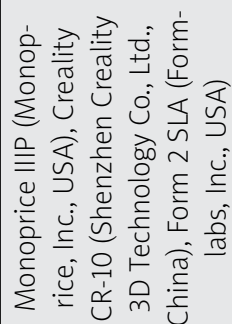 \\
\hline 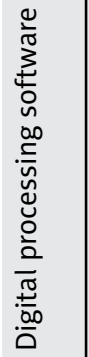 & 1 & 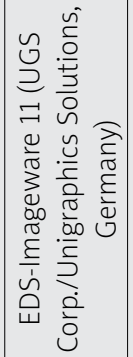 & 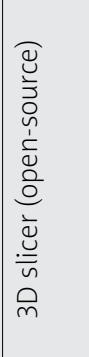 & 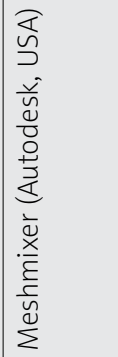 & 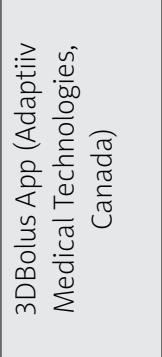 & I & 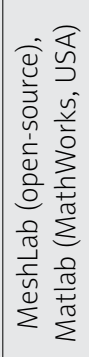 & 1 & 1 & 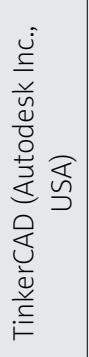 & 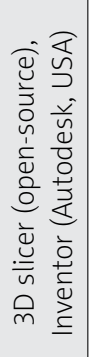 & 1 & 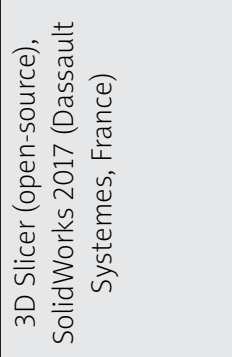 \\
\hline 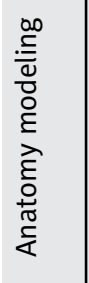 & 七 & 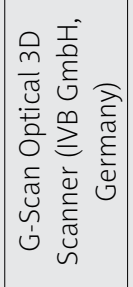 & 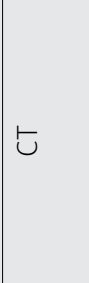 & 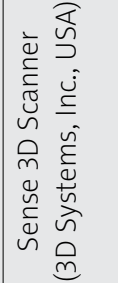 & $ち$ & 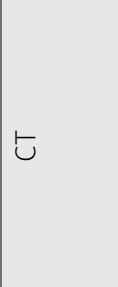 & ๖ & ¿̇ & 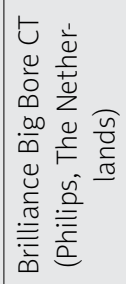 & $\dot{亡}$ & 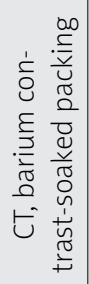 & $\dot{\sum}$ & $\longleftarrow$ \\
\hline 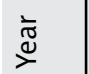 & $\begin{array}{l}\infty \\
\stackrel{0}{\sim}\end{array}$ & ঃ & $\stackrel{n}{\stackrel{n}{\sim}}$ & 官 & 完 & $\stackrel{n}{\stackrel{n}{N}}$ & $\stackrel{n}{\stackrel{n}{0}}$ & 完 & 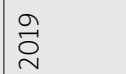 & $\begin{array}{l}\stackrel{0}{0} \\
\vec{N}\end{array}$ & $\stackrel{n}{\stackrel{n}{D}}$ & $\begin{array}{l}0 \\
\stackrel{\sim}{0}\end{array}$ & 完 \\
\hline 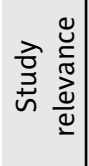 & 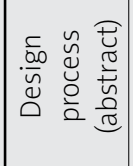 & 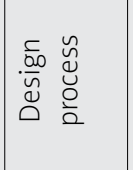 & 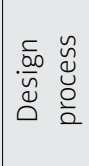 & 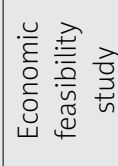 & 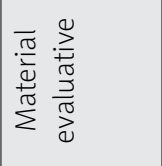 & 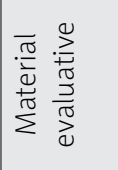 & 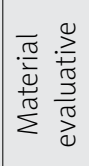 & 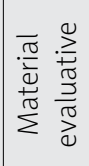 & 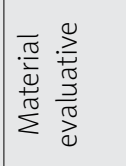 & 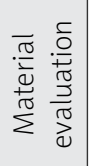 & 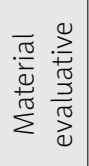 & 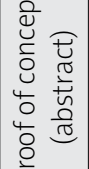 & 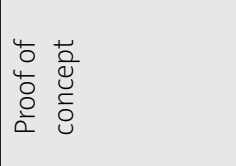 \\
\hline 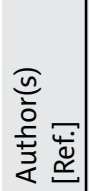 & 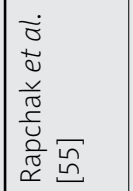 & 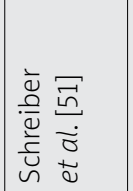 & 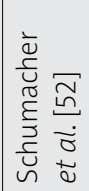 & 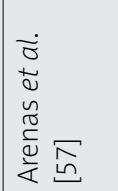 & 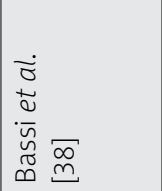 & 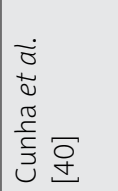 & 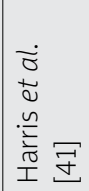 & 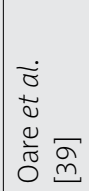 & 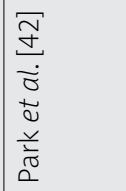 & 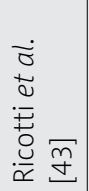 & 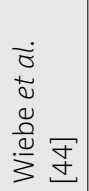 & 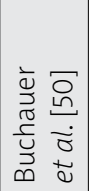 & 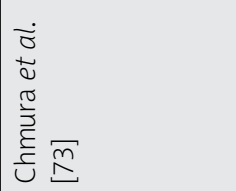 \\
\hline
\end{tabular}




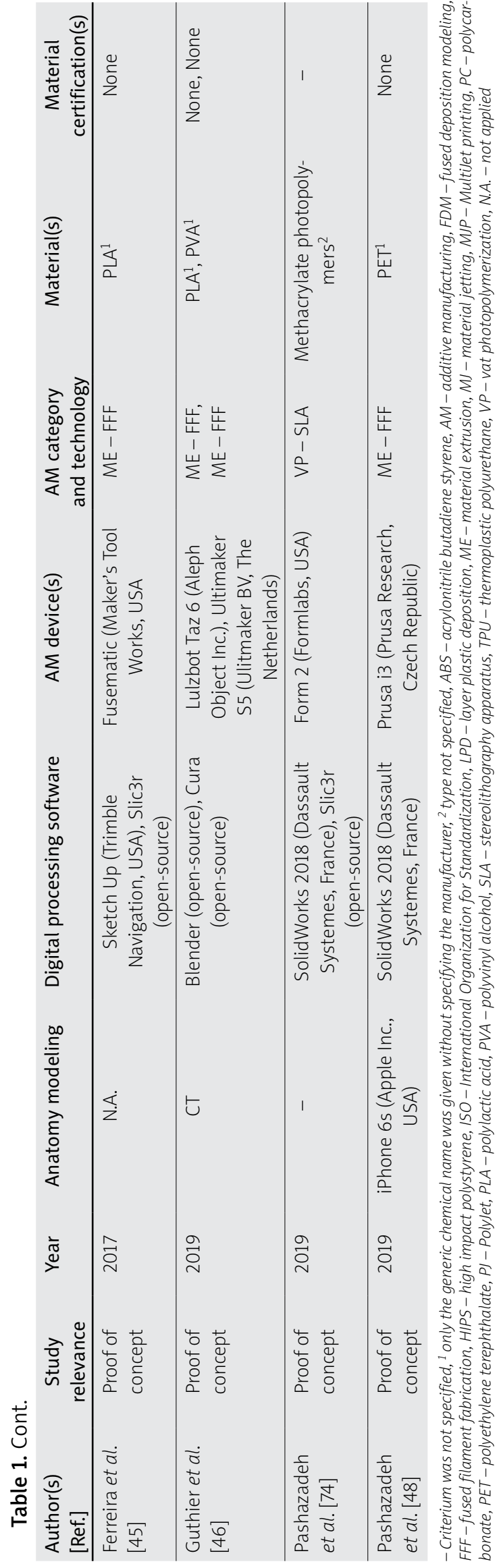

sions of the site can be obtained using alginate, from which a positive cast can be formed, laser scanned, virtually augmented with catheter lumen, and finally printed as a different material [32]. Moreover, this process eliminates the need for an initial CT scan.

\section{Digital processing of patient's data}

Digital processing converts the raw images into a $3 \mathrm{D}$ model, which can be smoothed and modified to remove artefacts. The area of treatment is then delineated, and catheters' tracks are plotted through a designed applicator object. Several software types may be required to perform all these tasks. To start, the initial image is processed and stored as a 3D model, notably a 'mesh'. MeshLab and Blender, among others, are open-source computer-aided design (CAD) and modeling software capable of processing meshes. The actual standard file type for 3D models in AM is STL, that which was used for the original stereolithography files in 1986. Nowadays, that all AM technologies are capable of using this file type, the component terms of standard tessellation language or standard triangle language have been retroactively applied to the STL acronym [71]. Other common file types include OBJ, AMF, and 3MF [72]. With DICOM files, open-source software, such 3D Slicer, has modules to design printable objects within the scan. After a design is specified, the models are then converted into G-code, a set of print instructions ranging from infill percentage to slice thickness, by the appropriate slicing software. Specialized medical software from vendors, such as MIM Software Inc. (Cleveland, Ohio, USA) and Adaptiiv Medical Technologies Inc. (Halifax, Nova Scotia, Canada) can integrate directly with commercial treatment planning systems for digital processing and conversion to print-compatible file types. Table 1 lists the software noted in recent publications in AM for superficial BT [30-46, 48, 51-53, 55-57, 73, 74].

Within the digital design process, several practical considerations would dictate catheter placement within the mould for the target volume. The orientation of the source paths should be limited to avoid travelling over or near organs at risk (OARs; such as the eye). Access to the after-loader may also influence the direction of the connector end of the catheters to avoid the transfer tube resting on the patient. Lumen path curvature should be designed in a way that follows the minimum radius of curvature specification of the remote afterloader. The source paths are generally forward-planned, based on the expertise of radiation oncologist, medical physicist, or brachytherapist. Several groups have developed computer algorithms to optimize BT catheter paths as well as dwell positions, in the hope of eliminating the need for human oversight [75-77]. To date, however, inverse optimization of catheter paths have not been implemented for superficial BT.

\section{Physical printing}

Once the STL file has been generated, a selection of printer types must be made. For skin BT, the two dominant AM device technologies are FFF/FDM and SLA. 

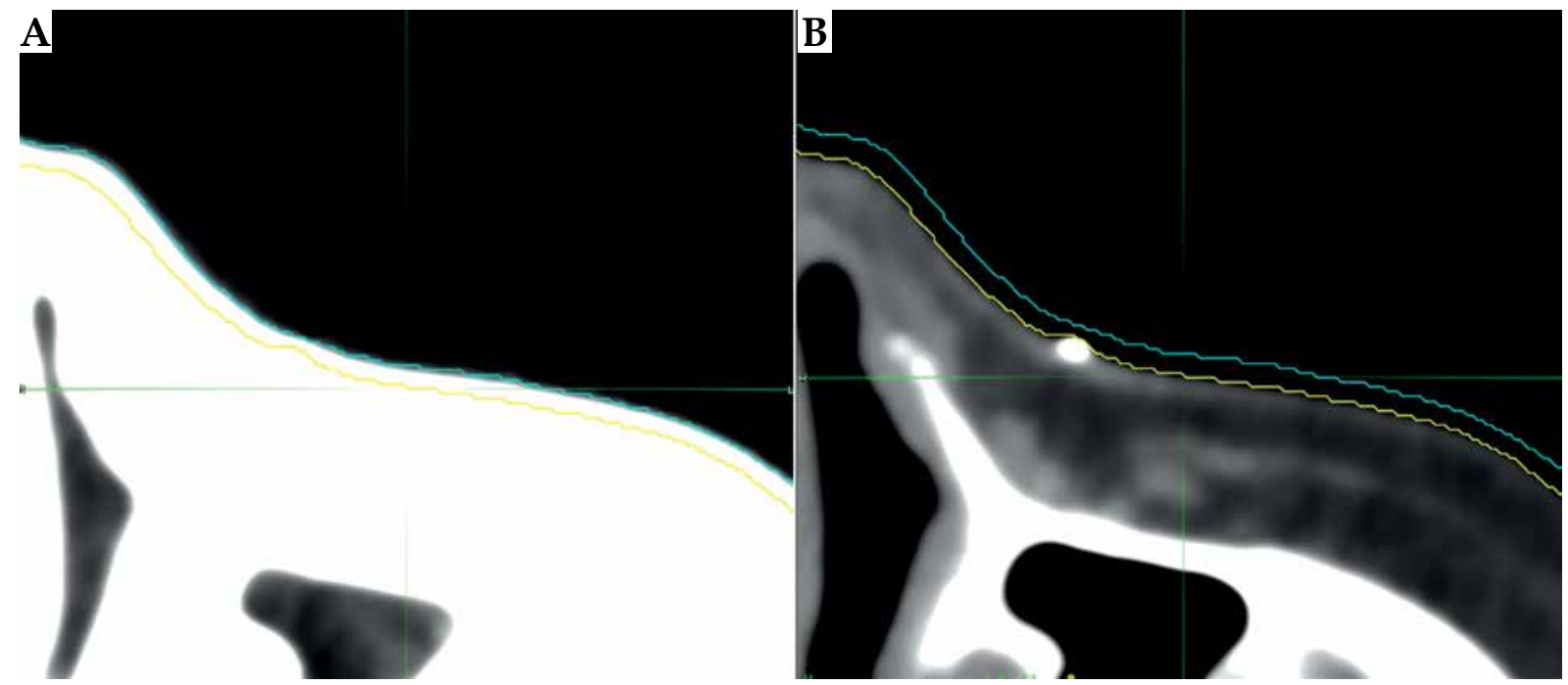

Fig. 2. The effect of window/level adjustments on determining the extent of skin on CT images. The outer blue line is the outline of skin surface using a lung window/level (A), while the inner yellow line is the outline of skin surface using a soft tissue window/level (B). This figure is composed of original images

These can be differentiated based on the achievable resolution of the printed products. In general, FFF/FDM printers can achieve resolutions on the order of 178-330 $\mu \mathrm{m}$, while SLA printers typically achieve 50-125 $\mu \mathrm{m}$ [65]. SLA printed applicators are often smoother and more accurate than FFF/FDM techniques [78]. The amount of material chosen to fill the object, known as 'infill percentage', will affect fabrication speed and can have a limited effect on the dosimetric property of the applicator as well [43]. Most AM technologies, however, are rapidly improving, and achievable resolutions and fabrication speed continue to increase.

Printing skin BT applicators is still mostly a manual design and verification process with limited vendor support. A typical workflow of superficial BT in AM is shown in Figure 3. As the field evolves, the hope is that a treatment planning system will offer a method to create STL files or AM applicators directly from the planned treatment; thereby, further reducing the discrepancy between the predicted and delivered dose distributions. Currently, the design of AM applicators is still based on experience; though, this is now performed digitally - inverse anatomy-based optimization of the mould and lumens is presently unavailable for skin BT.

\section{Quality assurance - materials and moulds \\ Materials}

In radiation therapy $\mathrm{AM}$, several polymer types have been used extensively. For FFF/FDM applicators, these materials include commercial variants of polycarbonate (PC), acrylonitrile butadiene styrene (ABS), thermoplastic polyurethane (TPU), polylactic acid (PLA), and high impact polystyrene (HIPS) [65]. For SLA applicators, there are several UV-activated photopolymers with various physical properties as well, although these are seen less frequently in radiation oncology applications, pos- sibly due to printer and material costs. Material clarity can have an impact on usability of a skin brachytherapy applicator, as optically clear parts are easier to assess for flaws, contact with the skin, and accurate placement over the target lesion. Also, each material type has commercial variants that are certified for their biocompatibility and compatibility with sterilization.

\section{Biocompatibility}

Biocompatibility describes the interactions of biomedical devices with biological tissue. This testing is essential when novel medical devices are to be placed in or on the body. Additionally, the United States Pharmacopeia (USP) provides standards for in vivo materials biocompatibility testing and classification. The USP classifications range from class I to class VI, depending on the requirements for biological inertness; class I is approved for use primarily on the skin and can be potentially harmful if placed within the body, whereas class VI materials are approved for permanent deep-tissue applications. AM applicators that are intended for skin BT can be categorized as surface devices with limited contact duration (i.e., $<24$ hours). Therefore, the USP material's requirements for skin brachytherapy are at least class I for uncompromised skin contact devices. Note that USP classification testing is viewed by some as a minimum requirement for medical devices. The International Organization for Standardization (ISO) 1009-1 provides more comprehensive set of tests to consider in the evaluation of biocompatibility of medical devices [79]. As examples, materials, such as PC-ISO from Stratasys Ltd. (Eden Prairie, Minnesota, USA) and Accura ClearVue from 3D Systems Inc. (Rock Hill, South Carolina, USA) both have USP class VI approval, while PC-ISO is also ISO 10993-1 rated [80, 81]. Using non-certified plastics may still be feasible if a certified biocompatible coating is added, or as non-clinical tools [41]. Preventing harm to the patient through adverse materials interactions is only the first step in material's selection. 
A
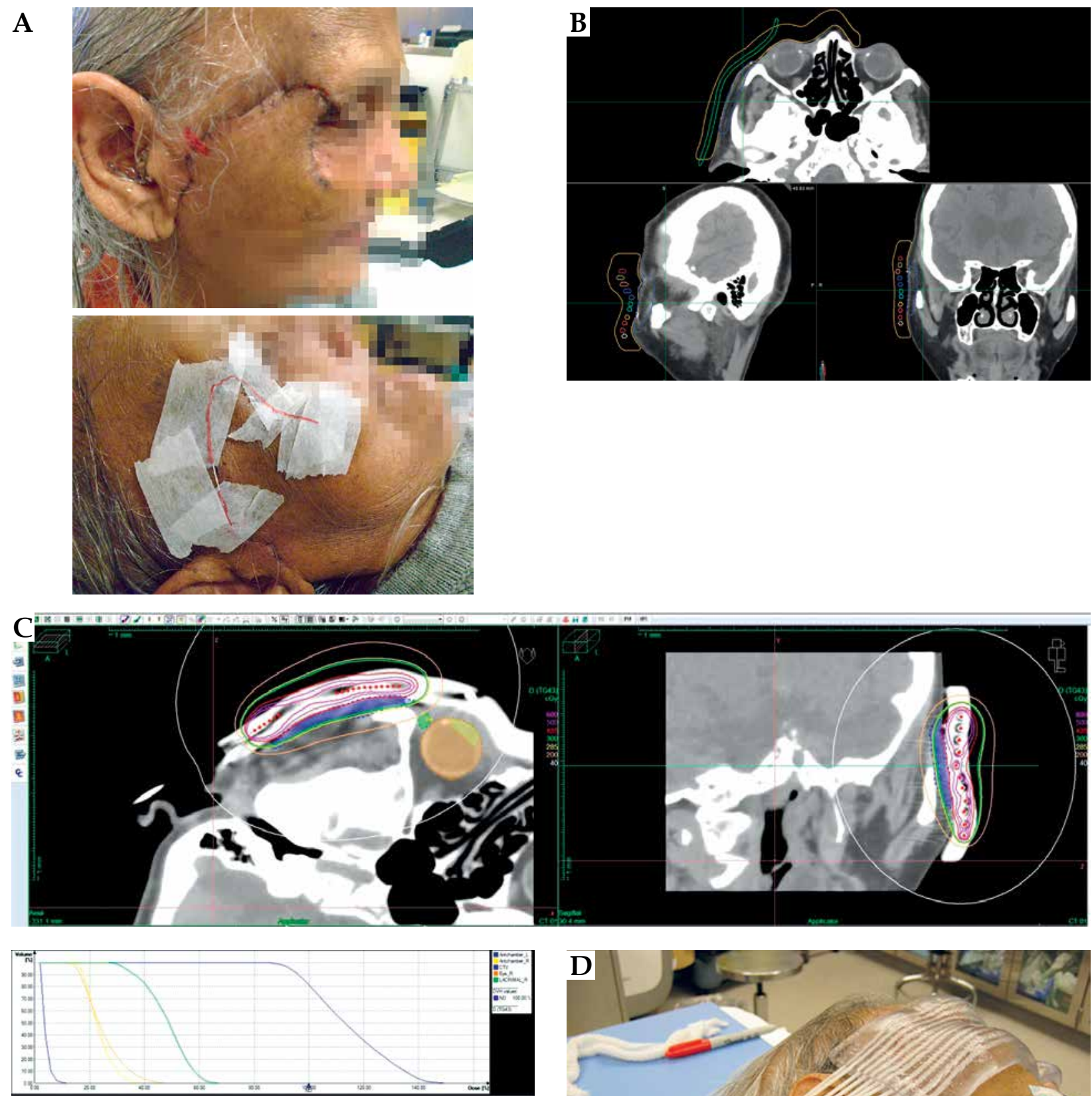
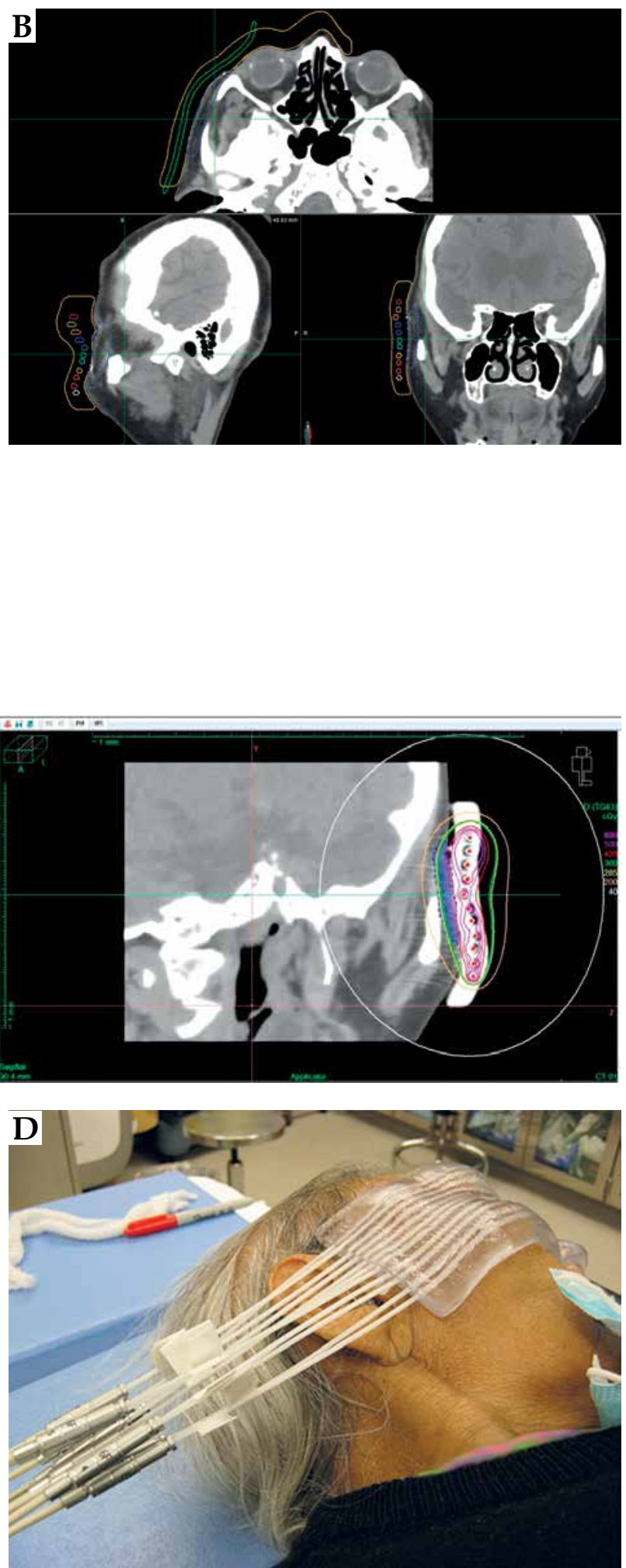

Fig. 3. An overview of the superficial brachytherapy process in additive manufacturing (AM). A) The surgical scar of the treatment area is lined with a fiducial wire. B) The patient is given a pre-planning CT scan. The applicator is digitally designed over the delineated clinical target volume (CTV; in blue) in MIM TPS (MIM Software Inc., USA), and the catheters' channels (in multi-color) are manually placed in Oncentra TPS (Elekta, Sweden). C) The applicator is printed and placed on the patient for the planning CT. MIM TPS was used to define the target and organs at risk. Oncentra Brachy TPS was used to create the treatment plan. The DVH highlights the wide range of doses across the CTV. D) Treatment with patient-specific AM applicator. Note: The applicator was manufactured by Agile Manufacturing Inc. (Uxbridge, Canada) using a stereolithography device and the Accura ClearVue material (3D Systems, Inc., USA). This figure is composed of original images 


\section{Sterilization}

The extent, to which a material can be decontaminated is another essential factor that impacts materials' selection for medical devices. While commercial ISO-certified materials for AM may be listed as 'sterilizable', this refers to the raw materials and not necessarily the printed object. This is particularly problematic for BT applicators given their form, which include long lumens of varying curvature approximately $2 \mathrm{~mm}$ in diameter.

Unlike most BT procedures, superficial BT of intact-skin lesions using customized applicators for each patient does not need to be sterilized. A low-level disinfectant is recommended by the Centre for Disease Control (CDC) for sterilization of medical devices in contact with the skin [82]. For printed superficial BT applicators, this involves placing the AM applicator in a vat of an enzymatic cleaning agent, such as ortho-phthalaldehyde (OPA), a high-level disinfectant with good material compatibility [83], in between fractions. Care should be taken to ensure that the chemicals used would not affect the material or the integrity of the print. In instances where the applicator could meet breached or significantly compromised surfaces, sterilization of the applicator prior to use should be considered. For many common AM materials in medicine, hydrogen peroxide $(\mathrm{HO})$ gas plasma is the recommended sterilization substance because of its high sterility rate and absence of mechanical damage to the print during the process [84]. In contrast, high heat sterilization, such as autoclaving, can warp a 3D print. Each print should be inspected thoroughly after sterilization.

\section{Physical assessment}

Independent verification of the dimensional accuracy of the printed applicators and the lumen are important, as they are often distorted from the digital model. Harris et al. observed that there was as much as a $0.8 \mathrm{~mm}$ difference between the planned and physical lumen sizes, and the reproducibility of the catheter placement within the lumen varied by $0.5 \mathrm{~mm}$, on average. These variations were most pronounced at the lumen openings, so a viable option to reduce this source of variation would be to taper the lumens at these points [41]. Ensuring that catheters can pass freely through the lumen is also essential. Vendor-supported catheters should be inserted into the AM applicators and be the only material that encounters the source. The catheter tubing ensures that the source never contacts uncured material and never jeopardize the retraction of a stuck source. The geometry of the print should be assessed on the verification and planning CT scans, ensuring appropriate infill and internal structure integrity. Producing an acceptable print is highly related to parameter choice and printer calibration [46]. Still, imperfections or inaccuracies should be considered during the planning process.

\section{Assessing dosimetric quality of materials}

A primary consideration when using different materials as customized applicators is conducting proper do- simetric assessments of the material. For superficial BT purposes, applicator materials must be dosimetrically water-equivalent, possessing the same attenuation properties, given that TG-43 formalism assumes this property of tissues used in dose calculations [85]. A general method to test for water-equivalency has been proposed by Cunha et al. [40]. In addition to water-equivalency, treatment planning calculated doses through printed materials must match actual delivered doses. Water-equivalency and treatment planning dose comparisons can be checked using radiochromic film measurements. Several studies have reported on the dosimetric properties of various AM materials, specifically the dose fall-off over appropriate distances and through different material thicknesses [38-44]. In each study, the authors declared the tested material water-equivalent, possessing comparable properties to a water-equivalent material, or measured dose through the material equivalent to those predicted by the treatment planning system (TPS).

Other studies have reported on water-equivalency of materials using ${ }^{192}$ Ir energies, such as PC-ISO (Stratasys Ltd., Eden Prairie, Minnesota, USA) as well as non-certified PLA and ABS, with each material determined to be water-equivalent [39-41]. Dosimetric testing of ABS by Ricotti et al. has also been performed using varying amounts of infill percentage. Infill percentage is the extent, to which a 3D print's internal portion is filled in, with less than $100 \%$ infill resulting in a honeycomb-like pattern of air gaps within the print. Ricotti et al. compared dose distributions among a commercial Freiburg flap, a replicated ABS flap printed with $10 \%$ infill and 3 parallelepipeds of the same thickness as the Freiburg flap, with $10 \%, 20 \%$, and $40 \%$ infills. The dose distribution of each AM applicator was in agreement with the commercial flap, showing that partially hollow low-cost material applicators do not adversely affect dose distributions [43]. Common AM applicator materials, even inexpensive ones, offer water-equivalent attenuation properties. The results of dosimetric testing methods on various materials using ${ }^{192}$ Ir sources and Gafchromic film (Ashland Inc., USA) are summarized in Table 2. Furthermore, material heterogeneities have been shown to be negligible for source distances less than $10 \mathrm{~cm}$ when using ${ }^{192} \operatorname{Ir}$ [86].

\section{Treatment planning}

The goal of the treatment planning process is to cover the target volume while sparing adjacent OARs and maintaining uniformity throughout the target volume. In general, in superficial skin BT, the dose is prescribed to 3-5 mm under the skin surface and the source is preferably placed $5 \mathrm{~mm}$ from the surface to avoid overdosing skin surface [10]. To date, there are ranges of prescription patterns in superficial BT, depending on the disease extent and selected applicator type. The American Brachytherapy Society recommends a dose between $40 \mathrm{~Gy} / 10$ fractions and $42 \mathrm{~Gy} / 6$ fractions [6]. Based on the literature and experts' opinion, a rough guide for treating lesions with a thickness of $3 \mathrm{~mm}$ is to place the catheters $3-5 \mathrm{~mm}$ from the surface. In cases where a sharper dose fall-off is required near adjacent OARs, a smaller offset for the cathe- 
Table 2. Dosimetric testing of additive manufacturing (AM) applicators for ${ }^{192}$ Ir superficial BT

\begin{tabular}{|c|c|c|c|c|c|c|}
\hline $\begin{array}{l}\text { Author } \\
\text { [Ref.] }\end{array}$ & ) AM material(s) & Dosimeter & $\begin{array}{c}\text { Analysis } \\
\text { tool }\end{array}$ & $\begin{array}{c}\text { Comparison } \\
\text { material }\end{array}$ & Results & Notes \\
\hline $\begin{array}{l}\text { Bassi } \\
\text { et al. } \\
{[38]}\end{array}$ & $\begin{array}{l}\text { Cheetah (Nin- } \\
\text { jaTek, USA) }\end{array}$ & $\begin{array}{c}\text { GafChromic film } \\
\text { EBT3 (Ashland Inc., } \\
\text { USA) }\end{array}$ & $\begin{array}{l}\text { PDD - } \\
\text { point } \\
\text { compari- } \\
\text { sons }\end{array}$ & Water & $\begin{array}{c}\text { Comparing results along } \\
7-30 \mathrm{~mm} \text { with and } \\
\text { without the material } \\
\text { present, the average } \\
\text { and maximum percent } \\
\text { depth dose differences } \\
\text { were } 2.2 \% \text { and } 4.7 \% \text {, } \\
\text { respectively }\end{array}$ & $\begin{array}{l}\text { The material was found to } \\
\text { be water-equivalent at }{ }^{192} \text { Ir } \\
\text { energies and in agreement } \\
\text { with TPS calculations }\end{array}$ \\
\hline $\begin{array}{l}\text { Cunha } \\
\text { et al. } \\
{[40]}\end{array}$ & $\begin{array}{l}\text { PC-ISO (Strata- } \\
\text { sys, Inc., USA) }\end{array}$ & $\begin{array}{l}\text { GafChromic film } \\
\text { EBT2 (International } \\
\text { Speciality Products, } \\
\text { now Ashland Inc., } \\
\text { USA) }\end{array}$ & $\begin{array}{l}\text { PDD - } \\
\text { point } \\
\text { compari- } \\
\text { sons; HU } \\
\text { - point } \\
\text { compari- } \\
\text { sons }\end{array}$ & Water & $\begin{array}{l}\text { PC-ISO is comparable } \\
\text { to water, based on }<1 \% \\
\text { difference in measure- } \\
\text { ments on PDD between } \\
1-6 \mathrm{~cm} \text {. The mean } \mathrm{HU} \\
\text { values were }-10 \text { and } \\
-1 \text { for the material and } \\
\text { water, respectively }\end{array}$ & $\begin{array}{c}\text { Small HU value difference } \\
\text { with water may be linked to } \\
\text { internal honeycomb pattern. } \\
\text { Note: this study does not } \\
\text { involve superficial BT directly } \\
\text { but it does test the material } \\
\text { used in [51] }\end{array}$ \\
\hline $\begin{array}{l}\text { Harris } \\
\text { et al. } \\
{[41]}\end{array}$ & $\begin{array}{l}\text { ABS (BitsFrom- } \\
\text { Bytes, UK) }\end{array}$ & $\begin{array}{l}\text { GafChromic film } \\
\text { EBT3 (Ashland Inc., } \\
\text { USA) }\end{array}$ & $\begin{array}{l}\text { PDD - } \\
\text { point } \\
\text { compari- } \\
\text { sons }\end{array}$ & Water & $\begin{array}{l}\text { From } 1-3 \mathrm{~cm} \text { and } 3-5 \mathrm{~cm} \\
\text { distance from source, } \\
\text { ABS had } \sim 1 \% \text { and } \sim 0.5 \% \\
\text { lower doses, respectively, } \\
\text { when compared to water }\end{array}$ & $\begin{array}{c}\text { A thorough analysis of } \\
\text { the physical material and } \\
\text { print properties was also } \\
\text { completed }\end{array}$ \\
\hline $\begin{array}{l}\text { Oare } \\
\text { et al. } \\
{[39]}\end{array}$ & $\mathrm{LA}^{1}$ & $\begin{array}{l}\text { GafChromic film } \\
\text { EBT3 (Ashland Inc., } \\
\text { USA) }\end{array}$ & $\begin{array}{l}\text { PDD - un- } \\
\text { certainty } \\
\text { analysis }\end{array}$ & Water & $\begin{array}{l}\text { Doses in measured in } \\
\text { both materials were } \\
\text { within the expected } \\
\text { uncertainty range }\end{array}$ & $\begin{array}{l}\text { According to the authors, } \\
\text { PLA and ABS can be used } \\
\text { instead of water for }{ }^{192} \text { Ir BT } \\
\text { film calibration }\end{array}$ \\
\hline $\begin{array}{l}\text { Park } \\
\text { et al. } \\
{[42]}\end{array}$ & $\begin{array}{l}\text { Dragon Skin } 10 \\
\text { (Smooth-On } \\
\text { Inc., USA), HIPS }\end{array}$ & $\begin{array}{l}\text { GafChromic film } \\
\text { EBT3 (Ashland Inc., } \\
\text { USA) }\end{array}$ & $\begin{array}{l}\text { PDD - } \\
\text { Gamma } \\
\text { analysis }\end{array}$ & Freiburg flap & $\begin{array}{l}\text { The elastic Dragon Skin } \\
\text { applicator showed the } \\
\text { highest gamma passing } \\
\text { rates when compared to } \\
\text { the other materials }\end{array}$ & $\begin{array}{l}\text { High passing rates for } \\
\text { Dragon Skin likely due to the } \\
\text { higher setup reproducibility } \\
\text { of the elastic material com- } \\
\text { pared to the others }\end{array}$ \\
\hline $\begin{array}{l}\text { Ricotti } \\
\text { et al. } \\
{[43]}\end{array}$ & $A B S^{1}$ & $\begin{array}{l}\text { GafChromic film } \\
\text { EBT3 (Ashland Inc., } \\
\text { USA) }\end{array}$ & $\begin{array}{l}\text { PDD - } \\
\text { Gamma } \\
\text { analysis }\end{array}$ & Freiburg flap & $\begin{array}{l}\text { No significant dose } \\
\text { distribution variations } \\
\text { found between the } \\
\text { ABS test parts and the } \\
\text { Freiburg flap }\end{array}$ & $\begin{array}{l}\text { Various infill percentages } \\
\text { and geometries were tested }\end{array}$ \\
\hline $\begin{array}{l}\text { Wiebe } \\
\text { et al. } \\
{[44]}\end{array}$ & $\begin{array}{l}\text { Accura Clear- } \\
\text { Vue (Stratasys, } \\
\text { Inc., USA) }\end{array}$ & $\begin{array}{l}\text { InLight nanoDot } \\
\text { Dosimeter (Lan- } \\
\text { dauer Inc., USA) }\end{array}$ & $\begin{array}{c}\text { Kerma } \\
\text { - point } \\
\text { compari- } \\
\text { sons }\end{array}$ & Water & $\begin{array}{l}\text { The total relative air } \\
\text { Kerma detected through } \\
\text { water, even though the } \\
\text { material was the same }\end{array}$ & $\begin{array}{l}\text { This study does not involve } \\
\text { superficial BT directly but it } \\
\text { does test the material used } \\
\text { in [32] }\end{array}$ \\
\hline
\end{tabular}

${ }^{1}$ Material brand was not specified, ABS - acrylonitrile butadiene styrene, HIPS - high impact polystyrene, PC - polycarbonate, PLA - polylactic acid

ters should be considered. Conversely, to treat at a greater depth, keeping the source away from the skin's surface may be beneficial. Such technique is used in Manchester skin BT method, in which individual mould or flap is placed over additional bolus of various thickness, pending clinical need [87]. Of course, tailoring the source distances across the skin is possible with a customized AM applicator. For commercial devices, such as the Freiburg flap, however, that distance to the surface remains fixed at $5 \mathrm{~mm}$ and the proximity to neighboring catheters is set at $10 \mathrm{~mm}$, limiting the amount of modulation available to treat complex surfaces. The American Brachytherapy Society provides some guidance on planning objectives, specifically in terms of hot spots on the skin surface, where they recommend that the dose should be limited to $125 \%$ for larger lesions treated by flaps and to $140 \%$ for smaller lesions considered custom moulds [6]. Treating skin lesions with superficial BT to a thickness beyond $5 \mathrm{~mm}$ is not recommended due to unacceptably high surface doses [6], although some centers would consider such method in lesions with thickness above $5 \mathrm{~mm}$ [88].

\section{Treatment and case studies}

Table 3 summarizes the case studies to date that are directly related to AM in superficial BT. In fitting with the appropriateness of using superficial BT to treat irregular topologies, noses are the most prevalent types treated with AM applicators according to various clinical research publications. One author noted that reproduc- 
Table 3. Published cases of additive manufacturing (AM) in skin brachytherapy

\begin{tabular}{lccccccc} 
Author(s) [Ref.] & Site & Disease & $\begin{array}{c}\text { No. of pa- } \\
\text { tients }\end{array}$ & $\begin{array}{c}\text { Dose } \\
(\text { Gy/fx. })\end{array}$ & $\begin{array}{c}\text { Rx depth } \\
(\mathrm{mm})\end{array}$ & $\begin{array}{c}\text { Surface dose } \\
(\text { Gy })\end{array}$ & Shielding \\
\hline Aldridge et al. [37] & Finger & - & 1 & - & - & - & - \\
\hline Casey et al. [31] & Left shin & BCC & 1 & $40 / 10$ (q.a.d.) & 5 & - & N.A. \\
\hline Clarke [30] & Nose & BCC & 1 & $55 / 20$ & - & - & Eyes \\
\hline D’Alimonte et al. [32] & Penis & SCC & 5 & $40 / 10$ & 5 & $44-65$ & N.A. \\
\hline Jones et al. [34] & Nose & - & - & - & - & - & Eyes \\
\hline Lecornu et al. [33] & Nose & BCC \& SCC & 2 & $36 / 6$ & - & $51.6,48$ & Eyes \\
\hline Taggar et al. [35] & Fingers (5) & Psoriasis & 1 & $16 / 12$ & 2 & 21.6 & Hand \\
\hline Voros et al. [36] & Penis & SCC & 5 & $40 / 10$ (b.i.d.) & - & - & N.A.
\end{tabular}

ibility of setup was actually better with an irregular topology and an AM applicator due to inherent indexing of the applicator on the anatomy and less risk of mispositioning compared to a flat surface [38]. Lecornu et al. identified that to facilitate placement on facial sites, constructs that would enable elastics loops for around the ears or head are useful in applicator's design [33].

\section{Economics and institutional risk considerations}

Implementation costs are a major factor when considering AM technologies in radiation oncology. In one superficial BT study, AM applicators were shown to be less expensive and more efficient than manual applicator fabrication techniques [57]. Materials and equipment come in a range of qualities and costs. Lecornu et al. purchased a printer for a fixed cost of 5,000 Euros, and incremental costs of 10 Euros for each applicator [33]. Conversely, Harris et al. proved that lower cost printers (< 500 US\$) and materials can be employed effectively for accurate $\mathrm{AM}$ applicator creation; however, biocompatibility and sterility of the non-certified materials were not considered in this study [41]. AM produces applicators that are more consistent and take less time than manual applicator construction [54]. In one study, the manual labor hours required for $\mathrm{AM}$ compared to manual methods were 6.25 hours and 9.50 hours, respectively [57]. Still, many barriers exist to prevent the implementation of AM workflows within the clinic. Time to implement, staff training, and expertise required to achieve consistently accurate results are the barriers to more widespread use of AM techniques in radiation oncology [58]. For some centers, these concerns combined with patient's volume considerations and the initial cost outlay for the printing hardware raises the question of outsourcing the process. Outsourcing the printing and leveraging the skills and superior equipment of a specialized AM provider may prove most economical, if the required number of prints each year is relatively low. Researchers in [32], [35], and [44] from the Sunnybrook Health Sciences Centre relied on an external company to create higher quality SLA applicators after designing them in-house. Still, this expertise would come at a premium, as noted by Lancellotta et al. [89].

Every institution has risk mitigation programs often prescribed via their insurance providers, which would impose restrictions on the AM skin BT program. It is imperative before beginning an AM skin BT program that institutional consents for producing medical equipment internally are fully approved and supported. Outsourcing or having processes in place for printed moulds for irregular surfaces as well as re-usable, standard moulds for flat skin surfaces are also worth considering [57].

\section{Conclusions}

Additive manufacturing applicators are attractive alternatives to standard superficial BT approaches. AM applicators enable the treatment of skin BT sites that would otherwise pose challenging for conventional methods. They have the main advantage of tailoring the applicator to be individualized to a patient's unique anatomy. Furthermore, AM applicators have the potential to improve the accuracy of treatments, while simplifying the process to create the applicators. However, with the implementation of any new technology, a rigorous quality assurance program should be developed alongside the clinical program.

\section{Disclosure}

The authors report no conflict of interest.

\section{References}

1. Albert MR, Weinstock MA. Keratinocyte carcinoma. CA Cancer J Clin 2003; 53: 292-302.

2. Karimkhani C, Boyers LN, Dellavalle RP et al. It's time for "keratinocyte carcinoma" to replace the term "nonmelanoma skin cancer". J Am Acad Dermatol 2015; 72: 186-187.

3. Skin cancer statistics. World Cancer Research Fund 2018. https:/ / www.wcrf.org/dietandcancer/cancer-trends / skin-cancer-statistics (accessed October 15, 2020).

4. Christensen SR, Wilson LD, Leffell DJ. Chapter 90: Cancer of the skin. In: DeVita VT, Lawrence TS, Rosenberg SA (eds.). DeVita, Hellman, and Rosenberg's Cancer: Principles and Practice of Oncology. $11^{\text {th }}$ ed. Lippincott Williams \& Wilkins, Philadelphia 2019.

5. What are basal and squamous cell skin cancers? Types of skin cancer. https://www.cancer.org/cancer/basal-andsquamous-cell-skin-cancer/about/what-is-basal-and-squamous-cell.html (accessed June 1, 2020).

6. Ouhib Z, Kasper M, Perez Calatayud J et al. Aspects of dosimetry and clinical practice of skin brachytherapy: The 
American Brachytherapy Society working group report. Brachytherapy 2015; 14: 840-858.

7. Rodriguez S, Santos M, Richart J et al. High-dose-rate brachytherapy in skin cancers: Patient convenience, local control and cosmetical results. Brachytherapy 2008; 7: 159.

8. Joslin C, Flynn A, Hall E. Principle and practice of brachytherapy using afterloading systems. Cancer Radiother 2001; 5: 787

9. Skowronek J. Brachytherapy in the treatment of skin cancer: an overview. Postepy Dermatol Alergol 2015; 32: 362-367.

10. Guinot JL, Rembielak A, Perez-Calatayud J et al. GECESTRO ACROP recommendations in skin brachytherapy. Radiother Oncol 2018; 126: 377-385.

11. Zaorsky NG, Lee CT, Zhang E et al. Skin cancer brachytherapy vs external beam radiation therapy (SCRiBE) meta-analysis. Radiother Oncol 2018; 126: 386-393.

12. Zaorsky NG, Lee CT, Zhang E et al. Hypofractionated radiation therapy for basal and squamous cell skin cancer: A metaanalysis. Radiother Oncol 2017; 125: 13-20.

13. Guix B, Finestres F, Tello J et al. Treatment of skin carcinomas of the face by high-dose-rate brachytherapy and custom-made surface molds. Int J Radiat Oncol Biol Phys 2000; 47: 95-102.

14. Arenas M, Arguís M, Díez-Presa L et al. Hypofractionated high-dose-rate plesiotherapy in nonmelanoma skin cancer treatment. Brachytherapy 2015; 14: 859-865.

15. Delishaj D, Laliscia C, Manfredi B et al. Non-melanoma skin cancer treated with high-dose-rate brachytherapy and Valencia applicator in elderly patients: a retrospective case series. J Contemp Brachytherapy 2015; 7: 437-444.

16. Gauden R, Pracy M, Avery AM et al. HDR brachytherapy for superficial non-melanoma skin cancers. J Med Imaging Radiat Oncol 2013; 57: 212-217.

17. Tormo A, Celada F, Rodriguez S et al. Non-melanoma skin cancer treated with HDR Valencia applicator: clinical outcomes. J Contemp Brachytherapy 2014; 6: 167-172.

18. Somanchi BV, Stanton A, Webb M et al. Hand function after high dose rate brachytherapy for squamous cell carcinoma of the skin of the hand. Clin Oncol (R Coll Radiol) 2008; 20: 691-697.

19. Svoboda VH, Kovarik J, Morris F. High dose-rate microselectron molds in the treatment of skin tumors. Int J Radiat Oncol Biol Phys 1995; 31: 967-972.

20. Ota K, Adar T, Dover L et al. Review: the reemergence of brachytherapy as treatment for non-melanoma skin cancer. J Dermatolog Treat 2018; 29: 170-175.

21. Köhler-Brock A, Prager W, Pohlmann S et al. The indications for and results of HDR afterloading therapy in diseases of the skin and mucosa with standardized surface applicators (the Leipzig applicator). Strahlenther Onkol 1999; 175: 170-174.

22. Kuncman Ł, Kozłowski S, Pietraszek A et al. Highly conformal CT based surface mould brachytherapy for non-melanoma skin cancers of earlobe and nose. J Contemp Brachytherapy 2016; 8: 195-200.

23. Fulkerson RK, Perez-Calatayud J, Ballester F et al. Surface brachytherapy: Joint report of the AAPM and the GEC-ESTRO Task Group No. 253. Med Phys 2020; 47: e951-987.

24. Kowalik Ł, Łyczek J, Sawicki M et al. Individual applicator for brachytherapy for various sites of superficial malignant lesions. J Contemp Brachytherapy 2013; 5: 45-49.

25. Types of non-melanoma skin cancer. Canadian Cancer Society. https://www.cancer.ca:443/en/cancer-information/cancer-type/skin-non-melanoma/non-melanoma-skin-cancer/ types-of-non-melanoma/?region=on (accessed June 1, 2020)

26. Canters RA, Lips IM, Wendling $M$ et al. Clinical implementation of 3D printing in the construction of patient specific bolus for electron beam radiotherapy for non-melanoma skin cancer. Radiother Oncol 2016; 121: 148-153.
27. Yoon K, Jeong C, Sung-woo K et al. Dosimetric evaluation of respiratory gated volumetric modulated arc therapy for lung stereotactic body radiation therapy using 3D printing technology. PLoS One 2018; 13: e0208685.

28. Loja MAR, Craveiro DS, Vieira L et al. Radiotherapy-customized head immobilization masks: from modeling and analysis to 3D printing. Nucl Sci Tech 2019; 30: 142.

29. Skinner L, Fahimian BP, Yu AS. Tungsten filled 3D printed field shaping devices for electron beam radiation therapy. PLoS One 2019; 14: e0217757.

30. Clarke S. 3D Printed surface applicators for high dose rate brachytherapy. Dalhousie University Halifax, Nova Scotia 2016.

31. Casey S, Bahl G, Awotwi-Pratt J et al. High dose rate 192-Ir-brachytherapy for basal cell carcinoma of the skin using a 3D printed surface mold. Cureus J Med Sci 2019; 11.

32. D'Alimonte L, Ravi A, Helou J et al. Optimized penile surface mold brachytherapy using latest stereolithography techniques: A single-institution experience. Brachytherapy 2019; 18: 348-352.

33. Lecornu M, Silva M, Barraux V et al. Digital applicator by 3D printing in contact brachytherapy. Cancer Radiother 2019; 23: 328-333.

34. Jones EL, Tonino Baldion $\mathrm{A}$, Thomas $\mathrm{C}$ et al. Introduction of novel 3D-printed superficial applicators for high-dose-rate skin brachytherapy. Brachytherapy 2017; 16: 409-414.

35. Taggar A, Martell K, Barnes E et al. 172 3D printed, individually customized high-dose-rate brachytherapy applicator for treatment of chronic digital psoriasis. Radiother Oncol 2019; 139: S73.

36. Voros L, Cohen GN, Piechocniski PW et al. Custom mold technique with 3D printed applicator "Shell" in penile HDR brachytherapy. Brachytherapy 2017; 16: S49-50.

37. Aldridge $\mathrm{S}$, Jones EL, Tonino A et al. Skin HDR brachytherapy treatment using a mould made with a $3 \mathrm{D}$ printer. Brachytherapy 2016; 15: S147-148.

38. Bassi S, Langan B, Malone C. Dosimetry assessment of patient-specific 3D printable materials for HDR surface brachytherapy. Phys Med 2019; 67: 166-175.

39. Oare C, Wilke C, Ehler E et al. Dose calibration of Gafchromic EBT3 film for Ir-192 brachytherapy source using 3D-printed PLA and ABS plastics. 3D Print Med 2019; 5: 3.

40. Cunha JAM, Mellis K, Sethi R et al. Evaluation of PC-ISO for customized, 3D printed, gynecologic 192-Ir HDR brachytherapy applicators. J Appl Clin Med Phys 2015; 16: 5168.

41. Harris BD, Nilsson S, Poole CM. A feasibility study for using ABS plastic and a low-cost 3D printer for patient-specific brachytherapy mould design. Australas Phys Eng Sci Med 2015; 38: 399-412.

42. Park SY, Kang S, Park JM et al. Development and dosimetric assessment of a patient-specific elastic skin applicator for highdose-rate brachytherapy. Brachytherapy 2019; 18: 224-232.

43. Ricotti R, Vavassori A, Bazani A et al. 3D-printed applicators for high dose rate brachytherapy: Dosimetric assessment at different infill percentage. Phys Med 2016; 32: 1698-1706.

44. Wiebe E, Easton $\mathrm{H}$, Thomas $\mathrm{G}$ et al. Customized vaginal vault brachytherapy with computed tomography imaging-derived applicator prototyping. Brachytherapy 2015; 14: 380-384.

45. Ferreira C, Johnson D, Rasmussen K et al. A novel conformal superficial high-dose-rate brachytherapy device for the treatment of nonmelanoma skin cancer and keloids. Brachytherapy 2017; 16: 215-222.

46. Guthier C, Devlin P, Harris T et al. Development and clinical implementation of semi-automated treatment planning including 3D printable applicator holders in complex skin brachytherapy. Med Phys 2019; 47: 869-879.

47. Sim L. Novel application of 3D printing in brachytherapy using MED610 3D printed insert for I-125 ROPES eye plaque. Australas Phys Eng Sci Med 2016; 39: 863-870. 
48. Pashazadeh A, Boese A, Friebe M. Surface anatomy leading to personalized surface applicator: 3D printing for brachytherapy of skin tumors, 2019. https://doi.org/10.18416/AMMM.2019.1909S03P21.

49. Pashazadeh A, Robatjazi M, Castro NJ et al. A multiwell applicator for conformal brachytherapy of superficial skin tumors: A simulation study. Skin Res Technol 2020; 26: 537-541.

50. Buchauer K, Henke G, Plasswilm L et al. EP-2020: Vertical type surface brachytherapy applicator improvement with a 3d printed dose compensation body. Radiother Oncol 2016; 119: S954.

51. Schreiber S, Reitemeier B, Herrmann T et al. A Process for making cutaneous radiation applicators based on digital data. Strahlenther Onkol 2006; 182: 349-352.

52. Schumacher M, Lasso A, Cumming I et al. 3D-printed surface mould applicator for high-dose-rate brachytherapy, 2015. https://doi.org/10.1117/12.2082543.

53. Douglass MJJ, Caraça Santos AM. Application of optical photogrammetry in radiation oncology: HDR surface mold brachytherapy. Brachytherapy 2019; 18: 689-700.

54. Bhaird SNA, Caines R, Lee C. OC-0322 HDR Skin applicator fabrication for clinical cases: handmade vs digitally designed and 3D printed. Radiother Oncol 2019; 133: S166-167.

55. Rapchak AK, Likhacheva AO, Page CM et al. Custom 3-D printed skin shielding for skin surface brachytherapy. Brachytherapy 2018; 17: S65.

56. Duckworth T, Wang H, Barbee D. Implementation of a Leipzig surface HDR treatment program with 3D printing. Brachytherapy 2017; 16: S96.

57. Arenas M, Sabater S, Sintas A et al. Individualized 3D scanning and printing for non-melanoma skin cancer brachytherapy: a financial study for its integration into clinical workflow. J Contemp Brachytherapy 2017; 9: 270-276.

58. Rooney MK, Rosenberg DM, Braunstein S et al. Three-dimensional printing in radiation oncology: A systematic review of the literature. J Appl Clin Med Phys 2020; 21: 15-26.

59. ISO/ASTM 52900:2015(en). Additive manufacturing - General principles - Terminology. https://www.iso.org/obp/ ui/\#iso:std:iso-astm:52900:ed-1:v1:en (accessed October 12, 2020).

60. Additive Manufacturing vs 3D Printing. GE Additive https://www.ge.com/additive/additive-manufacturing/ information/3d-printing (accessed June 1, 2020).

61. Chepelev L, Giannopoulos A, Tang A et al. Medical 3D printing: methods to standardize terminology and report trends. 3D Print Med 2017; 3: 4.

62. Gross BC, Erkal JL, Lockwood SY et al. Evaluation of 3D printing and its potential impact on biotechnology and the chemical sciences. Anal Chem 2014; 86: 3240-3253.

63. ASTM International. Standard terminology for additive manufacturing technologies: designation F2792-12a. West Conshohocken, PA: ASTM International; 2012.

64. What is additive manufacturing? Engineering Product Design. https://engineeringproductdesign.com/knowledge-base/additive-manufacturing-processes/ (accessed June 1, 2020).

65. Tino R, Leary M, Yeo A et al. Additive manufacturing in radiation oncology: a review of clinical practice, emerging trends and research opportunities. Int J Extrem Manuf 2020 2: 012003 .

66. Sheynin D, Bovalino YM. This is what a 3D printed jet engine looks like. GE Reports 2017. https://www.ge.com/reports/ treat-avgeeks-inside-look-ges-3d-printed-aircraft-engine/ (accessed June 1, 2020).

67. Lin E, Alessio A. What are the basic concepts of temporal, contrast, and spatial resolution in cardiac CT? J Cardiovasc Comput Tomogr 2009; 3: 403-408.
68. Haleem A, Javaid Mohd. 3D scanning applications in medical field: A literature-based review. Clin Epidemiol Global Health 2019; 7: 199-210.

69. Sharma A, Sasaki D, Rickey DW et al. Low-cost optical scanner and 3-dimensional printing technology to create lead shielding for radiation therapy of facial skin cancer: First clinical case series. Adv Radiat Oncol 2018; 3: 288-296.

70. Sasaki DK, McGeachy P, Aviles JEA et al. A modern mold room: Meshing 3D surface scanning, digital design, and 3D printing with bolus fabrication. J Appl Clin Med Phys 2019; 20: 78-85.

71. Grimm T. User's guide to rapid prototyping. Society of Manufacturing Engineers 2004.

72. Most Common 3D Printer File Formats. All3DP 2020. https:// all3dp.com/1/3d-printer-file-format/ (accessed June 1, 2020).

73. Chmura J, Erdman A, Ehler E et al. Novel design and development of a 3D-printed conformal superficial brachytherapy device for the treatment of non-melanoma skin cancer and keloids. 3D Print Med 2019; 5: 10

74. Pashazadeh A, Boese A, Castro NJ et al. A new 3D printed applicator with radioactive gel for conformal brachytherapy of superficial skin tumors. $41^{\text {st }}$ Annual International Conference of the IEEE Engineering in Medicine and Biology Society (EMBC), 2019; 6979-6982.

75. Patil S, Pan J, Abbeel P et al. Planning curvature and torsion constrained ribbons in 3D with application to intracavitary brachytherapy. Automation Science and Engineering, IEEE Transactions On 2015; 12: 1332-1345.

76. Poulin E, Collins-Fekete CA, Létourneau M et al. Adaptation of the CVT algorithm for catheter optimization in high dose rate brachytherapy. Med Phys 2013; 40: 111724.

77. Guthier CV, Damato AL, Hesser JW et al. A fast inverse treatment planning strategy facilitating optimized catheter selection in image-guided high-dose-rate interstitial gynecologic brachytherapy. Med Phys 2017; 44: 6117-6127.

78. What Does Resolution Mean in 3D Printing? Formlabs https:/ / formlabs.com/blog/3d-printer-resolution-meaning/ (accessed June 1, 2020).

79. What is ISO 10993? How is it Different from USP Class VI? Holland Applied Technologies 2014. https://hollandaptblog.com/2014/04/22/what-is-iso-10993-how-is-it-different-from-usp-class-vi/ (accessed June 1, 2020).

80. Accura ClearVue. Materials. http://infocenter.3dsystems. com/materials/sla/accura-clearvue (accessed October 13, 2020).

81. Stratasys PC-ISO. Stratasys ${ }^{\mathrm{TM}}$ Support Center. https://support.stratasys.com/en/materials/fdm-materials/pc-iso (accessed October 13, 2020).

82. Disinfection \& Sterilization Guidelines. Guidelines Library. Infection Control. CDC 2019. https://www.cdc.gov/infectioncontrol/guidelines/disinfection/index.html (accessed June 14, 2020)

83. Bennett JE, Dolin R, Blaser MJ. Mandell, Douglas, and Bennett's principles and practice of infectious diseases. Elsevier 2019.

84. Perez M, Block M, Espalin D et al. Sterilization of FDM-manufactured parts. Corpus ID: 53468428.

85. Rivard MJ, Coursey BM, DeWerd LA et al. Update of AAPM Task Group No. 43 Report: A revised AAPM protocol for brachytherapy dose calculations. Med Phys 2004; 31: 633-674.

86. Melhus CS, Rivard MJ. Approaches to calculating AAPM TG-43 brachytherapy dosimetry parameters for 137Cs, 125I, 192Ir, 103Pd, and 169Yb sources. Med Phys 2006; 33: 1729 1737.

87. Rembielak A. Complex and prolonged skin toxicity after superficial brachytherapy for basal cell carcinoma on the lower leg. J Contemp Brachytherapy 2020; 12: 406-411. 
88. Kalaghchi B, Esmati E, Ghalehtaki R et al. High-dose-rate brachytherapy in treatment of non-melanoma skin cancer of head and neck region: preliminary results of a prospective single institution study. J Contemp Brachytherapy 2018; 10: 115-122.

89. Lancellotta V, Pagano S, Tagliaferri L et al. Individual 3-dimensional printed mold for treating hard palate carcinoma with brachytherapy: A clinical report. J Prosthet Dent 2019; 121: 690-693. 